\title{
Aeroservoelastic Design Definition of a 20 MW Common Research Wind Turbine Model
}

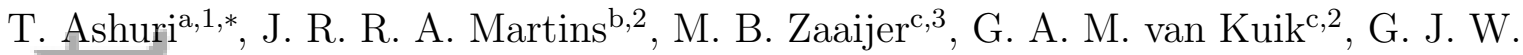 \\ van Bussel ${ }^{\mathrm{c}, 2}$ \\ ${ }^{a}$ University of Texas at Dallas, Department of Mechanical Engineering, Richardson, 75080 TX, \\ USA \\ = ${ }^{b}$ University of Michigan, Department of Aerospace Engineering, Ann Arbor, 48109 MI, USA \\ ${ }^{c}$ Delft University of Technology, Department of Aerodynamics and Wind Energy, Kluyverweg 1, \\ Delft, 2629 HS, The Netherlands
}

\begin{abstract}
Wind turbine upscaling is motivated by the fact that larger machines can achieve lower levelized cost of energy. However, there are several fundamental issues with the design of such turbines, and there is little public data available for large wind turbine studies. To address this need, we develop a $20 \mathrm{MW}$ common research wind turbine design that is available to public 1 . Multidisciplinary design optimization is used to define the aeroservoelastic design of the rotor and tower subject to the following constraints: blade-tower clearance, stresses, modal frequencies, tip-speed and fatigue damage at several sections of the tower and blade. For blade the design variables include blade length, twist and chord distribution, structural thicknesses distribution and rotor speed at the rated. The tower design variables are the height, and the diameter distribution in the vertical direction. For the other components, mass models are employed to capture their dynamic interactions. The associated cost of these components is obtained by using cost models. The design objective is to minimize the levelized cost of energy. The results of this research show the feasibility of a $20 \mathrm{MW}$ wind turbine, and provide a model with the corresponding data for wind energy researchers to use in the investigation of different aspects of wind turbine design and upsealing.
\end{abstract}

Keywords: Wind turbine aeroservoelasticity, multidisciplinary design optimization, common research wind turbine model, $20 \mathrm{MW}$ design, upscaling.

* Corresponding author

Email address: turaj.ashuri@utdallas.edu (T. Ashuri)

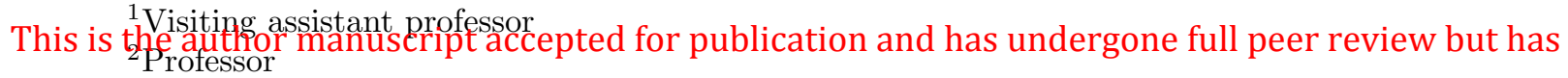
not beenAthistugh \$heresseyediting, typesetting, pagination and proofreading process, which may

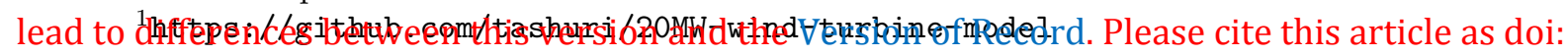
10.1002/we.1970

Preprint submitted to Wind Energy

January 18, 2016

This article is protected by copyright. All rights reserved. 


\footnotetext{
${ }^{4}$ The existing installation size are 5 to $7 \mathrm{MW}$, and 7 to $8 \mathrm{MW}$ turbines are currently being designed.

${ }^{5} \mathrm{~A}$ conventional architecture is a blade with a beam box that has two shear webs and two spar caps.
} 
advantage they might have. Therefore, there is a need for a publicly available large scale wind turbine design with the corresponding data for research projects. Such data could also help answer some of the questions in wind turbine design today, namely: (1) How large can we scale up a complete wind turbine (not just a single component), (2) What would be the design characteristics of a large wind turbine?, and (3) What would be an accurate estimate of the LCoE for larger turbines using the current technology?

To address these needs, we developed a $20 \mathrm{MW}$ common research wind turbine complete model and made it publicly available 6 . Unlike the previous studies, the design of this large wind turbine is performed using multidisciplinary design optimization (MDO), a well established design technique for the design of wind turbines [18]. The scaling law provides design for which there is no guarantee of feasibility. Furthermore, even if feasible, a scaled design will not be an optimal design solution. Therefore, the MDO methodology used in this research provides a feasible and optimum design for the $20 \mathrm{MW}$ turbine.

Since active control is becoming increasingly important for larger wind turbines, this work extends the previous optimization studies with no controller or a fixed controller strategy by updating controller parameters during every optimization iteration $[18,19,20,21,22,23,24]$. The integrated design of a controller enables the development of an economically more attractive large scale wind turbine by increasing energy capture using a controller that is optimized simultaneously with the rest of the design.

The majority of large scale wind turbines designed nowadays are upwind, threebladed, pitch-regulated, variable-speed turbines, and this is the focus of this research as well. To provide an initial set of design variables needed for the optimization to start with, the $5 \mathrm{MW}$ UpWind [4] wind turbine design data are upscaled to a $20 \mathrm{MW}$ design using scaling rules [25], and a scaling factor of two. After this step, optimization of the design takes place to provide the optimal preliminary data, such as rotor diameter, hub height, rated rotational speed, and structural and aerodynamic design of the tower and rotor.

To evaluate the LCoE as the design objective function, various components of the cost breakdown and the annual energy production (AEP) are needed. For several components of the cost breakdown, the WindPACT [26] heuristic cost models have been used. However, for the tower and rotor blade these cost models have not been used. Instead, the design variables of the tower and blade structures, such as the tower wall thickness and rotor chord are optimized. The cost contributions of these components to the $\mathrm{LCoE}$ are determined from the design variables' values. In particular, the mass is determined from the design variables and the costs are calculated from the mass. This approach gives the cost evaluation a much wider range of applicability than the heuristic, data dependent models. However, although the tower and blades are parametrically optimized for the $20 \mathrm{MW}$ scale, their concept and configuration are similar to those of current multi-megawatt turbines.

$6 \longdiv { \text { https://github.com/tashuri/20MW-wind-turbine-model } }$ 
These cost and mass models are either dependent or independent of the blade and tower design variables. Therefore, during the optimization process, the value of these dependent models is also adjusted to give an integrated design with the lowest LCoE. An example of a dependent model is the hub mass and cost, which depends on the blade mass. The independent models do not have any size dependency, and are therefore fixed for all sizes. The cost of the safety system is an example of a model that is independent of the size. Details of these models can be found in previous works [27, 28, 29, 30, 31], and are therefore not discussed here.

" The quantification of the AEP, the system masses, and the costs allows the LCoE to be calculated and used as a multidisciplinary objective function to be minimized. The solution of this optimization problem results a wind turbine design that includes rotor and tower data, cost and mass data, and the operational parameters of the wind turbine. The optimization is done for wind conditions at a Dutch site [32].

\section{MDO formulation}

To formulate a MDO problem, the choice of an optimization architecture, design variables and constraints, objective function and optimization algorithm needs to be defined. An architecture integrates the aeroservoelastic analysis method (to simulate the system under study) with optimizer, and it defines the data flow and computational process. This section outlines the MDO formulation, while the next section presents the aeroservoelastic analysis method.

\subsection{Optimization architecture}

Among the various optimization architectures described in the literature [33], this study uses multidisciplinary feasible design (MDF) architecture. In MDF, the optimizer is directly linked to the disciplinary solvers as depicted in Figure 1 using the extended design structure matrix (XDSM)convention [34]. The disciplinary solvers shown in this figure are described in Section 3.1.

\subsection{Design variables}

The $20 \mathrm{MW}$ wind turbine developed in this research has the following design features:

1. A three-bladed upwind rotor attached to a conical hub with $3 \mathrm{~m} / \mathrm{s}$ cut-in and $25 \mathrm{~m} / \mathrm{s}$ cut-out wind speed.

2. A collective PI pitch-to-feather controller for power regulation above the rated.

3. A variable-speed generator torque controller for energy maximization below the rated.

4. A geared drive train with a full converter.

5. A minimum of $25 \mathrm{~m}$ air-gap between the unloaded blade-tip and the ground.

6. A tubular tower concept nonlinearly tapered from the bottom to top.

To obtain the initial set of design variables needed for the optimization to start with, the $5 \mathrm{MW}$ UpWind wind turbine developed in the framework of the UpWind 


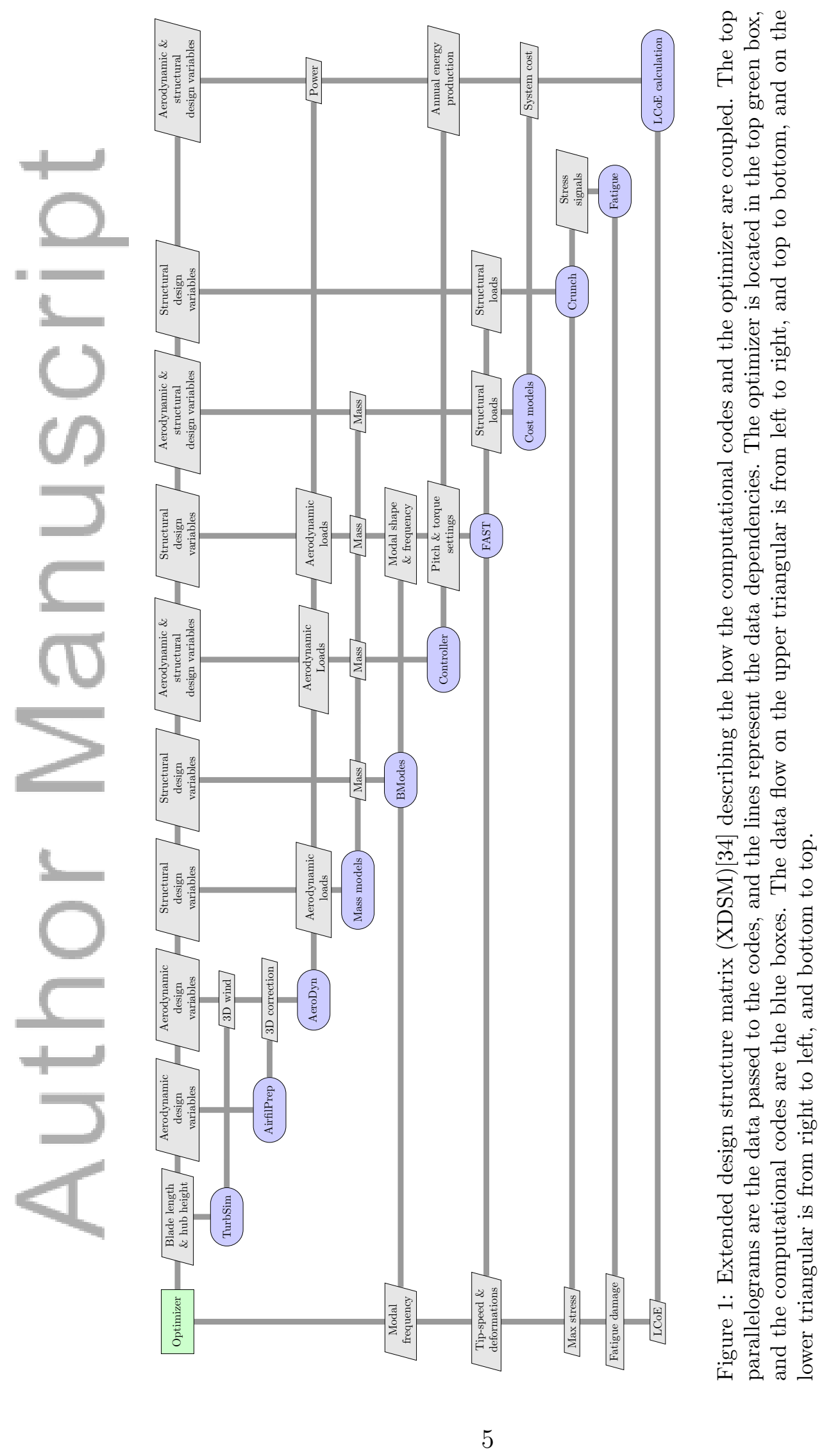

This article is protected by copyright. All rights reserved. 

optimized and further explained in Section 2.4.1.

Table 1: Blade and tower design variables for the initial and optimal designs, with corresponding upper and lower limits

\begin{tabular}{|c|c|c|c|c|c|}
\hline Variable (units) & Opt. level & Lower & Initial & Optimal & Upper \\
\hline Length of blade (m) & 1 & 110.0 & 123.0 & 135.0 & 140.0 \\
\hline Height of tower (m) & 1 & 150.0 & 175.2 & 155.0 & 190.0 \\
\hline Rotational speed at rated (rpm) & 1 & 6.0 & 6.4 & 7.1 & 7.5 \\
\hline Section 6, twist (deg) & 2 & 10.0 & 13.3 & 14.8 & 15.0 \\
\hline Section 10, twist (deg) & 2 & 5.0 & 10.2 & 5.8 & 11.0 \\
\hline Section 14 , twist (deg) & 2 & 2.0 & 3.3 & 3.1 & 5.0 \\
\hline Section 17, twist (deg) & 2 & 0.0 & 0.4 & 1.5 & 3.0 \\
\hline Section 20, twist (deg) & 2 & 0.0 & 0.0 & 0.1 & 2.0 \\
\hline Section 1 , chord $(\mathrm{m})$ & 2 & 6.0 & 7.1 & 7.6 & 8.0 \\
\hline Section 6 , chord (m) & 2 & 7.0 & 9.1 & 10.0 & 10.0 \\
\hline Section 10, chord $(\mathrm{m})$ & 2 & 6.0 & 8.0 & 6.7 & 9.0 \\
\hline Section 17, chord (m) & 2 & 2.0 & 4.6 & 2.9 & 6.0 \\
\hline Section 20, chord (m) & 2 & 0.1 & 0.2 & 1.6 & 2.5 \\
\hline Section 1 , skin thickness $(\mathrm{cm})$ & 2 & 18.0 & 20.0 & 19.0 & 21.0 \\
\hline Section 3, skin thickness $(\mathrm{cm})$ & 2 & 10.0 & 12.0 & 18.9 & 21.0 \\
\hline Section 6, skin thickness $(\mathrm{cm})$ & 2 & 4.0 & 4.6 & 17.1 & 20.0 \\
\hline Section 16, skin thickness $(\mathrm{cm})$ & 2 & 2.0 & 3.0 & 16.2 & 20.0 \\
\hline Section 3, web thickness $(\mathrm{cm})$ & 2 & 1.5 & 2.0 & 14.5 & 20.0 \\
\hline Section 6, web thickness $(\mathrm{cm})$ & 2 & 2.0 & 4.0 & 16.0 & 20.0 \\
\hline Section 16 , web thickness $(\mathrm{cm})$ & 2 & 2.0 & 2.6 & 15.2 & 20.0 \\
\hline Section 3, spar thickness $(\mathrm{cm})$ & 2 & 1.0 & 2.0 & 14.4 & 20.0 \\
\hline Sēction 6 , spar thickness $(\mathrm{cm})$ & 2 & 1.0 & 5.0 & 13.2 & 20.0 \\
\hline Section 16, spar thickness $(\mathrm{cm})$ & 2 & 1.0 & 4.8 & 10.0 & 20.0 \\
\hline Section 1, tower diameter $(\mathrm{m})$ & 2 & 9.0 & 12.0 & 10.0 & 15.0 \\
\hline Section 7, tower diameter $(\mathrm{m})$ & 2 & 8.0 & 12.0 & 9.0 & 15.0 \\
\hline Section 14, tower diameter $(\mathrm{m})$ & 2 & 6.0 & 9.8 & 6.9 & 12.0 \\
\hline Section 22, tower diameter $(\mathrm{m})$ & 2 & 5.0 & 8.2 & 6.2 & 10.0 \\
\hline
\end{tabular}

There are 22 design variables for the rotor. These variables are the external geometry (11), structural thickness (10), and rotor rotational speed (1). The geometry variables are 5 chord lengths at section 1 (blade root), 6, 10,17 and 20 (blade tip), 
blade length, and 5 twist angles at section 6,10,14, 17 and 20. The structural thicknesses of the composite lay-ups are 3 spar thicknesses at section 3, 6 and 16, 4 shell thicknesses at section 1, 3,6,16, and 3 web thicknesses at section 3,6 and 16. The rotational speed of the rotor and the blade length together define the tip-speed of the blade, which is considered as a design constraint.

The five design variables of the tower are the tower height (1), and the diameter at sections 1 (tower bottom), 7, 14 and 22 (tower top). We assumed a fixed diameter to thickness ratio of 160 to find the value of thickness at the sections where the diameter optimization takes place. This is common practice in the oil and gas industry to design against pile buckling at the conceptual and preliminary design phases [36, 37]. This design variable linking technique not only reduces the computational time, but also prevents buckling. All these design variables are continuous.

Table 6 lists the exact locations of each blade section, and Table 14 list the locations for the tower sections. For the blade, these sections are measured from the blade root (section 1) to the tip (section 20), and for the tower they start at the tower bottom (section 1) and end up at the tower top (section 22). Cubic interpolation is employed to find the distributed properties of the blade and tower between these sections. To have a smooth and continuous interpolation of the section design variables, the following parameters are predefined:

1. Sections 1 to 3 (root region) have a circular cross section with equal diameter for these sections.

2. The twists for sections 1 trough 6 are equal. These sections serve to transition from the circular root section to an airfoil shape, and they do not contribute in a significant way to power generation.

3. Shear web and cap thicknesses close to the blade root (sections 1 and 2) are zero.

\subsection{Design constraints}

Several inequality constraints are used to obtain a feasible design solution of the blade and tower as detailed in Tables 2 and 3 . The design constraints of the blade are fatigue damage at five sections along the blade, stresses, blade-tower clearance, and the first three natural frequencies. The design constraints of the tower are fatigue damage and stress at six sections along the tower, and the first and second natural frequencies.

Partial safety factors are used in combination with these constraints to cover the design and modeling uncertainties. Table 4 shows the selected values for the partial safety factors, except for the design load case 2.3 (see Table 8), where a partial safety factor of 1.1 for the ultimate limit state is used.

\subsection{Objective function}

$\mathrm{LCoE}$ is a representative multidisciplinary objective function that reflects the tradeoffs between all disciplines, and results in a true assessment of all the technical and economical changes. For a single wind turbine operating in a wind farm, LCoE contains 
Table 2: Turbine blade design constraints (accounting for safety factors)

\begin{tabular}{ll}
\hline Constraint & Value (units) \\
\hline Tip-deflection & $\leq 18.3(\mathrm{~m})$ \\
Section $1,3,6,10,17,20$ flapwise fatigue & $\leq 0.7(-)$ \\
Section $1,3,6,10,17,20$ edgewise fatigue & $\leq 0.7(-)$ \\
Section $1,3,6,10,17,20$ flapwise stress & $\leq 276(\mathrm{MPa})$ \\
Section $1,3,6,10,17,20$ edgewise stress & $\leq 276(\mathrm{MPa})$ \\
$1^{\text {st }}$ frequency & $2.1 P \leq \omega_{1 n} \leq 2.9 P(\mathrm{~Hz})$ \\
$2^{\text {nd }}$ frequency & $\omega_{2 n} \geq 3.1 P(\mathrm{~Hz})$ \\
$3^{\text {rd } \text { frequency }}$ & $\omega_{3 n} \geq 3.1 P(\mathrm{~Hz})$ \\
Tip-speed & $\leq 120(\mathrm{~m} / \mathrm{s})$ \\
\hline
\end{tabular}

Table 3: Tower design constraints (accounting for safety factors)

\begin{tabular}{ll}
\hline Constraint & Value (units) \\
\hline \hline Section 1, 5, 9, 13, 17, 21 stress (fore-aft) & $\leq 333(\mathrm{MPa})$ \\
Section $1,5,9,13,17,21$ fatigue damage (fore-aft) & $\leq 0.7(-)$ \\
$1^{\text {st }}$ frequency & $1.1 P \leq \omega_{1 n} \leq 1.9 P(\mathrm{~Hz})$ \\
$2^{\text {nd }}$ frequency & $\omega_{1 n} \geq 3.1 P(\mathrm{~Hz})$ \\
\hline
\end{tabular}

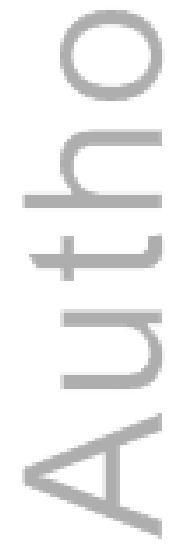

Table 4: Partial safety factors 38

\begin{tabular}{ll}
\hline Type of safety factor & Value \\
\hline \hline Material & 1.05 \\
Failure consequence & $\begin{array}{l}\text { Blade } 1.0 \\
\text { Tower } 1.0\end{array}$ \\
Ultimate limit state & 1.35 \\
Fatigue limit state & 1.43 \\
Modal frequency & $\pm 0.1 P$ \\
\hline
\end{tabular}


the following elements [26]: Turbine capital cost (TCC), balance of station (BOS), initial capital cost (ICC), levelized replacement cost (LRC) and operations and maintenance (OM) costs. Note that in the calculation of the BOS, we did not consider any transportation cost, since the WindPACT model estimates an unrealistically high transportation cost for large wind turbines.

These cost models were calculated based on the cost of materials and products for year 2002, and are adjusted in this research based on the cost of materials and products to account for inflation according to the producer price index 7 . The combination of these cost models and the AEP enables the calculation of LCoE as:

$$
\mathrm{LCoE}=\left(\frac{\mathrm{ICC} \times \mathrm{IR}+\mathrm{LRC}+\mathrm{OM}}{\mathrm{AEP}}\right),
$$

where IR is the interest rate with a value of 0.118 . AEP is the yearly energy production, which can be written as,

$$
A E P \approx 8760 \sum_{i=\text { cut-in }}^{\text {cut-out }} P\left(V_{i}\right) f\left(V_{i}\right),
$$

where $P(V)$ is the turbine power curve, 8760 is the total number of hours in a year, $i$ is the wind speed index that ranges from the cut-in to cut-out speeds, with an interval of $2 \mathrm{~m} / \mathrm{s}$. The wind probability distribution function $f(V)$ is calculated using,

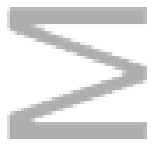

$$
f(V)=\left(\frac{k}{c}\right)\left(\frac{V}{c}\right)^{k-1} \exp \left[-\left(\frac{V}{c}\right)^{k}\right],
$$

where $k$ is the shape factor, $V$ is the wind speed, and $c$ is the wind speed scale factor. Here, $c=9.47$ and $k=2$. An AEP conversion loss of $5.6 \%$ is assumed (for the mechanical-to-electrical energy conversion in the drive train), which is the same as the DOWEC design at the rated power [39].

\subsubsection{Optimization algorithm and implementation}

There are several factors that make the present design optimization computationally expensive: (1) The simultaneous design optimization of the blade and tower with several design variables and constraints; (2) The use of time domain simulation of the wind turbine with multiple design load cases to capture the dynamic behavior, and (3) The required gradients of the objective function and design constraints, which are computed using finite differences. To save computational time, the design variables are decomposed, resulting in a bi-level optimization approach. In both optimization levels, LCoE is minimized but with respect to different sets of variables.

For the first level, the convex linearization (CONLIN) algorithm is used [40]. For the second level of the optimization process, we use the Lagrange multiplier

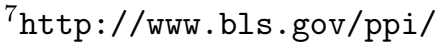


method [41]. The level one optimization process runs quickly since there is only one design constraint is enforced (the blade tip-speed), and the design variables are only tower height, blade length, and rated rotational speed.

The second level optimization starts with the optimized values from the level one optimized tower height, blade length, and rated rotational speed. All the other design variables are optimized subject to all the design constraints. This iterative process between the two levels continues until the specified convergence of $1 \%$ in the $\mathrm{LCoE}$ value is achieved. This tolerance is achieved after four iterations of the bi-level optimization, each having 10 to 14 iterations for level 1, and 25 to 32 iterations for level 2. The total optimization time was 1,150 hours of wall time using 40 computing cores.

\section{Aeroservoelastic analysis method}

This section outlines the components of the aeroservoelastic analysis, which are based on different disciplinary solvers to simulate the dynamics of the wind turbine. In addition to describing the disciplinary solvers, we also present the aerodynamic and structural design definition, load cases, and applied safety factors.

\subsection{Disciplinary solvers}

Wind turbines are multidisciplinary systems and thus several disciplinary solvers are needed to simulate the dynamics of the whole system. This paper uses the NREL series of disciplinary solvers, since they are all publicly available. Table 5 lists the solvers used in this work. Details of the wrapping and coupling of these solvers are given by Ashuri et al. [18]

Table 5: Computational codes used simulate the wind turbine aeroservoelastics

\begin{tabular}{llc}
\hline Code & Application & Reference \\
\hline \hline TurbSim & Modeling the flow field & {$[42$} \\
AeroDyn & Modeling the aerodynamic loading & {$[43]$} \\
AirfoilPrep & Modifying airfoil polar for 3-D effects & {$[44$} \\
FAST & Modeling the dynamics response of the turbine & {$[45]$} \\
BModes & Computing modal data & {$[46]$} \\
Crunch & Analyzing the time-series & {$[47]$} \\
Fatigue & Computing the fatigue damage & {$[48]$} \\
\hline
\end{tabular}

\subsection{Controller design}

A variable-speed, variable-pitch-to-feather controller is used in this research. The strategy to control the power production is based on the design of two separable control algorithms [49]: a generator torque controller for the partial and transition load region, and a full-span rotor-collective blade pitch controller for the full load region. 


\subsection{Aerodynamics and structural design definition}

The planform of the blade has nonlinear taper from the maximum chord location at section 6 to the blade tip. The cross section changes from circular in section 1 to an airfoil shape at section 6 . The $20 \mathrm{MW}$ turbine uses eight different airfoil types for thelblade. The first three airfoils near the root have a circular cross section with a drag coefficients of 0.55 and no lift. The next two airfoils have an elliptic cross section that has a drag coefficient of 0.39 , and no lift. The remaining six airfoils are Delft University (DU) and NACA airfoils. Table 6 shows the type and location of all airfoils along the blade.

The airfoils are designed for a Reynolds number of 20 million at the clean condition of the rotor [50]. To do this analysis, we use the airfoil design code RFOIL [51, 52. Then the methods of Du and Selig [53] and Eggers et al. [54 are used for the rotational stall delay. The drag coefficient is corrected using the method of Viterna and Janetzke [44]. Finally, the Beddoes-Leishman dynamic-stall hysteresis parameters are estimated [55]. AirfoilPrep is used to do these modifications on the airfoil properties (see Table 5) before running the time domain simulations.

The internal structure of the blade consists of a beam box with two spar caps at the bottom and top, and two shear webs between them as shown in Figure 2, with a skin surrounding this box. We made no assumptions about the core, adhesive, bonding, resin, foam and other elements of the blade. However, the contribution of these nonstruetural elements to the blade properties have implicitly been included, since blade mass and stiffness are dependent on the structural dimensions through a correlation model based on the $5 \mathrm{MW}$ reference turbine.

The tower has a circular cross section along the entire height. Table 7 lists the choice of the materials and their properties for the blade and tower, excluding the safety factors. These data are based on typical values found in engineering literature.

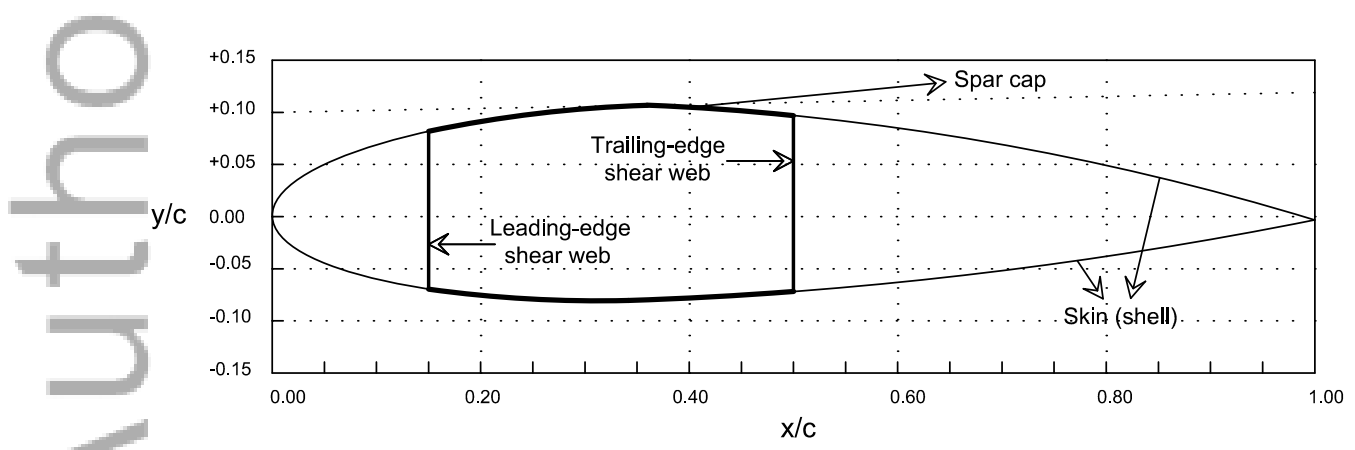

Figure 2: Structural layout of the turbine blade

An analytic model developed by Ashuri et al. [56] is used to obtain the flapwise and edgewise stiffnesses, and the mass per unit length of the blade based on the material 
Table 6: Airfoil distribution along the turbine blade span

\begin{tabular}{|c|c|c|c|}
\hline Section & Airfoil & Distance from root $(\mathrm{m})$ & Pitch axis position (\%chord) \\
\hline 1 & Circular & 0.000 & 50.0 \\
\hline 2 & Circular & 2.613 & 50.0 \\
\hline & Circular & 7.020 & 50.0 \\
\hline & Elliptic & 11.407 & 46.0 \\
\hline 5 & Elliptic & 15.795 & 42.0 \\
\hline 6 & DU00W401 & 20.182 & 39.0 \\
\hline 7 & DU00W401 & 24.583 & 37.5 \\
\hline & DU00W401 & 28.971 & 37.5 \\
\hline & DU00W350 & 33.358 & 37.5 \\
\hline & DU00W350 & 39.946 & 37.5 \\
\hline & DU97W300 & 53.122 & 37.5 \\
\hline 12 & DU91W2250 & 66.285 & 37.5 \\
\hline 13 & DU93W210 & 79.461 & 37.5 \\
\hline 14 & NACA64618 & 92.623 & 37.5 \\
\hline 15 & NACA64618 & 105.799 & 37.5 \\
\hline 16 & NACA64618 & 118.975 & 37.5 \\
\hline 17 & NACA64618 & 125.550 & 37.5 \\
\hline 18 & NACA64618 & 128.844 & 37.5 \\
\hline 19 & NACA64618 & 132.138 & 37.5 \\
\hline 20 & NACA64618 & 135.000 & 37.5 \\
\hline
\end{tabular}

properties of Table 7 and the geometry of each cross section. The torsional degree of freedom is assumed to be rigid. These properties are inputs to the aeroelastic solver and used to model the dynamic response of the blade.

A structural damping ratio of $0.477465 \%$ (critical in all modes of the isolated blade) that is equal to a $3.0 \%$ logarithmic decrement - similar to the $5 \mathrm{MW}$ UpWind turbine is assumed for the blade in the time domain analysis [4]. For the tower, the structural damping ratio is $\mathbf{1 . 0 \%}$ for all the tower modes (first and second of the fore-aft and side-side modes as used for the simulations).

\subsection{Design load cases}

For the fatigue loads, a normal turbulence model (NTM) is selected for the power production mode, and applied from the cut-in to cut-out wind speed with a reference period of 630 seconds (the first 30 seconds are ignored to ensure that all the transient behaviors are damped out). Since the partial damage contribution from all different directions is accumulated in one direction, the calculated fatigue is an overestimate and yields a conservative design. Such a unidirectional fatigue damage calculation 
is also allowed based on IEC design standards because it is conservative. Due to this assumption, only the fore-aft fatigue damage at the tower is used as a design constraint, as shown in Table 3.

For extreme loads, DLC 1.3, 2.3, 3.3, 5.1, and 6.1 are considered. Table 8 lists the defined load cases. The IEC-1B class is used for these load cases [57]. For DLC 2.3, an extreme operating gust combined with a grid drop is considered as the fault.

\section{Results}

" In this section, we describe the main design characteristics of the $20 \mathrm{MW}$ wind turbine that resulted from our multidisciplinary design optimization.

\subsection{Cost estimation}

Table 9 lists the cost and mass data of the $20 \mathrm{MW}$ wind turbine. As the table shows, the LCoE of the $20 \mathrm{MW}$ wind turbine is estimated to be $0.0345 \mathrm{USD} / \mathrm{kWhr}$, with an AEP of 86 GWhr.

\subsection{Design variables and constraints}

Table 1 lists the initial, optimum, and upper and lower bounds for all the design variables. Linear scaling is employed to find the initial set of design variables. The initial values of the linearly upscaled design variables allow an engineering judgment to be made on the upper and lower bounds of these variables to establish a design space that is neither computationally expensive nor to bounded.

As explained before, we enforce several design constraints. However, only active constraints (those that govern the design) are presented. For the blade, the active constraints are the tip-deflection and fatigue damage at the root. Similarly, for the optimum tower, fatigue is an active constraint, which is typically the case for structures subjected to turbulent wind loading. Further information on the design constraint trends has been detailed in previous work [58, 59, 60, 61, 62, 63]. Table 10 lists the active design constraints for both the blade and tower at the optimum.

\subsection{Blade data}

Figure 3 shows a schematic view of the wind turbine compared to the largest manmade space rocket, Saturn V, to show the relative scale of the two designs. As the

Table 7: Composite blade and metal tower material properties

\begin{tabular}{lccccc}
\hline $\begin{array}{l}\text { Structural } \\
\text { element }\end{array}$ & $\begin{array}{c}\text { Young modulus } \\
(\mathrm{GPa})\end{array}$ & $\begin{array}{c}\text { Density } \\
\left(\mathrm{kg} / \mathrm{m}^{3}\right)\end{array}$ & $\begin{array}{c}\text { Yield stress } \\
(\mathrm{MPa})\end{array}$ & $\begin{array}{c}\text { S-N slope } \\
(-)\end{array}$ & $\begin{array}{c}\text { S-N intercept } \\
(\mathrm{MPa})\end{array}$ \\
\hline \hline Blade skin & 17 & 510 & 276 & 11 & 190 \\
Blade web & 17 & 510 & 276 & 11 & 190 \\
Blade spar & 32 & 690 & 276 & 11 & 190 \\
Tower & 215 & 7800 & 333 & 5 & 235 \\
\hline
\end{tabular}


Table 8: Definition of the design load cases based on the IEC standard

\begin{tabular}{lccccc}
\hline $\begin{array}{l}\text { Modeled } \\
\text { scenario }\end{array}$ & $\begin{array}{c}\text { Load } \\
\text { case }\end{array}$ & $\begin{array}{c}\text { Wind } \\
\text { speed }(\mathrm{m} / \mathrm{s})\end{array}$ & $\begin{array}{c}\text { Yaw } \\
\text { error }\end{array}$ & $\begin{array}{c}\text { No. of } \\
\text { seeds }\end{array}$ & $\begin{array}{c}\text { Load } \\
\text { type }\end{array}$ \\
\hline \hline Power generation & 1.2 & 3 to 25 & 0 & 9 & Fatigue \\
Power generation & 1.3 & 3 to 25 & $\pm 5.6,0$ & 9 & Ultimate \\
Power generation and fault & 2.3 & 9 to 13,25 & 0 & 6 & Ultimate \\
Start up & 3.3 & 3,9 to 13,25 & 0 & 3 & Ultimate \\
Emergency shut down & 5.1 & 9 to 13,25 & 0 & 6 & Ultimate \\
Parked situation & 6.1 & $V_{50}$ & $\pm 8.0,0$ & 6 & Ultimate \\
\hline
\end{tabular}

figure shows, the $20 \mathrm{MW}$ wind turbine has three $135 \mathrm{~m}$ blades. Table 11 presents the blade data. The shown mass distribution adds up to a total blade mass of 259.0 tonnes. The natural frequencies of the blade corresponding to the first and second out-of-plane, and the first in-plane modes are: $0.2860,1.0032$ and $0.6277 \mathrm{~Hz}$, respectively. Figure 4 shows the chord and twist distribution at different stations along the blade. This figure also presents the linearly upscaled blade chord and twist distribution. As the figure-shows, the linearly upscaled blade has a uniform distribution compared to the fully nonlinear distribution of the optimized blade.

Figure 5 shows the main aerodynamic properties of the rotor. These aerodynamic properties are obtained by running a series of simulations from the cut-in to cut-out wind speeds assuming a steady wind. The first 60 seconds of the simulations was ignored to ensure that all the transient behaviors were damped out, and the system reaches its steady state status. Using this steady model, a rated wind speed of $10.7 \mathrm{~m} / \mathrm{s}$ is obtained.

\subsection{Drive train data}

Table 12 lists the drive train gross properties for the $20 \mathrm{MW}$ wind turbine. The $20 \mathrm{MW}$ design has an optimum rated rotor speed of $7.15 \mathrm{rpm}$. With a fixed rated generator speed of $1173.7 \mathrm{rpm}$, a gearbox ratio of 164:1 is needed. Upscaling the properties of the $5 \mathrm{MW}$ UpWind design, results in an equivalent spring constant of $6.94 \times 10^{9} \mathrm{Nm} / \mathrm{rad}$, and an equivalent damping constant of $4.97 \times 10^{7} \mathrm{Nm} /(\mathrm{rad} / \mathrm{s})$ for the drive train.

\subsection{Nacelle and hub data}

Table 13 presents the optimal gross data of the hub and nacelle. From the mass models developed for the hub, we obtain a mass of 252.8 tonnes. We assume that the hub is made of ductile iron castings and has a spherical shape. Based on the wall thickness of the hub, the hub mass moment of inertia is $2.1 \times 10^{6} \mathrm{~kg} \mathrm{~m}^{2}$. The nacelle mass (mass of all tower top components except the rotor and hub) is 945.0 tonnes. 
Table 9: Cost data for the $20 \mathrm{MW}$ design in 2010 USD

\begin{tabular}{|c|c|c|}
\hline Equipment & Cost $\left(\times 10^{3} \mathrm{USD}\right)$ & Mass (tonnes) \\
\hline Blade & 4051.7 & 259.0 \\
\hline $\mathrm{Hub}$ & 1456.9 & 252.8 \\
\hline Pitch system & 1945.3 & 236.0 \\
\hline Hub cone & 34.6 & 4.6 \\
\hline Main shaft & 1605.3 & 159.1 \\
\hline Shaft bearing & 1013.4 & 42.5 \\
\hline Gearbox & 4955.5 & 161.9 \\
\hline Drive train brake & 44.4 & 4.0 \\
\hline Generator & 1592.2 & 59.8 \\
\hline Electronics & 1572.8 & - \\
\hline Yaw system & 1495.0 & 176.8 \\
\hline Nacelle frame & 752.6 & 280.8 \\
\hline Nacelle railing & 414.2 & 35.1 \\
\hline Nacelle cover & 279.6 & 23.4 \\
\hline Turbine connection (electrical) & 1235.5 & - \\
\hline Cooling and hydraulic system & 309.0 & 1.6 \\
\hline Monitoring and safety system & 65.4 & - \\
\hline Tower & 3971.0 & 1588.3 \\
\hline Turbine capital costs (TCC) & 34898.2 & - \\
\hline Foundation & 290.7 & - \\
\hline Installation & 363.1 & - \\
\hline Farm connection (electrical) & 838.2 & - \\
\hline Site assessment and permits & 934.5 & - \\
\hline Balance of station (BOS) & 2426.5 & - \\
\hline Initial capital cost (ICC) & 37324.7 & - \\
\hline Levelized replacement cost & 249.3 & - \\
\hline Maintenance and operation & 108.7 & - \\
\hline Interest rate & 0.1185 & - \\
\hline Annual energy production (GWhr) & 86.0 & - \\
\hline Levelized cost of energy (USD/kWhr) & 0.0345 & - \\
\hline
\end{tabular}

Table 10: Functional constraints of the blade and tower

\begin{tabular}{llr}
\hline Description (unit) & Constraint & Optimum \\
\hline \hline Tip-deflection $(\mathrm{m})$ & $\leq 18.3$ & 18.1 \\
Fore-aft fatigue at tower base $(-)$ & $\leq 0.70$ & 0.7 \\
Edgewise fatigue at the blade root $(-)$ & $\leq 0.70$ & 0.7 \\
\hline
\end{tabular}




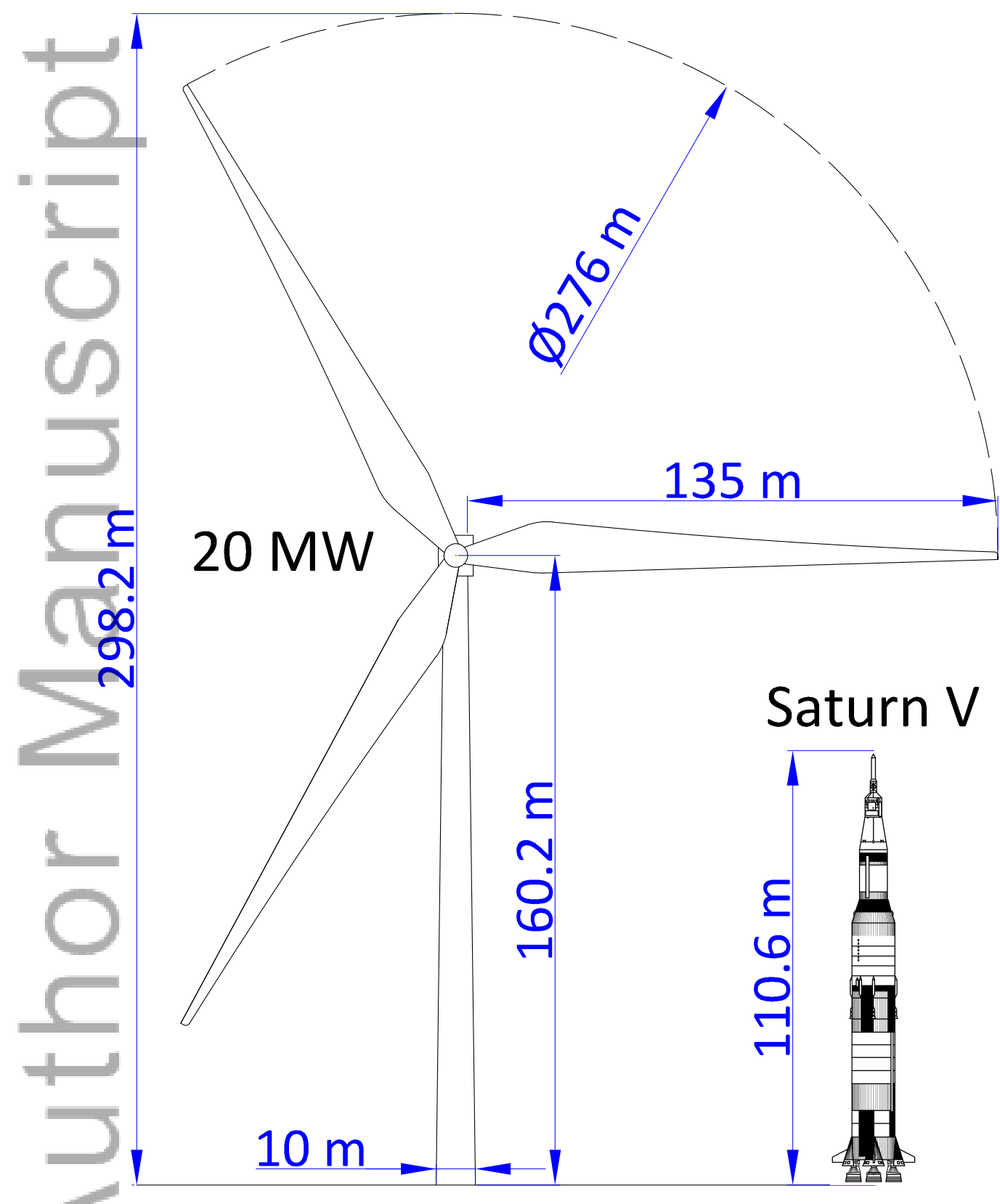

Figure 3: A schematic view of the $20 \mathrm{MW}$ wind turbine and comparison of its size with the Saturn $\mathrm{V}$ rocket as the largest space rocket ever made. 


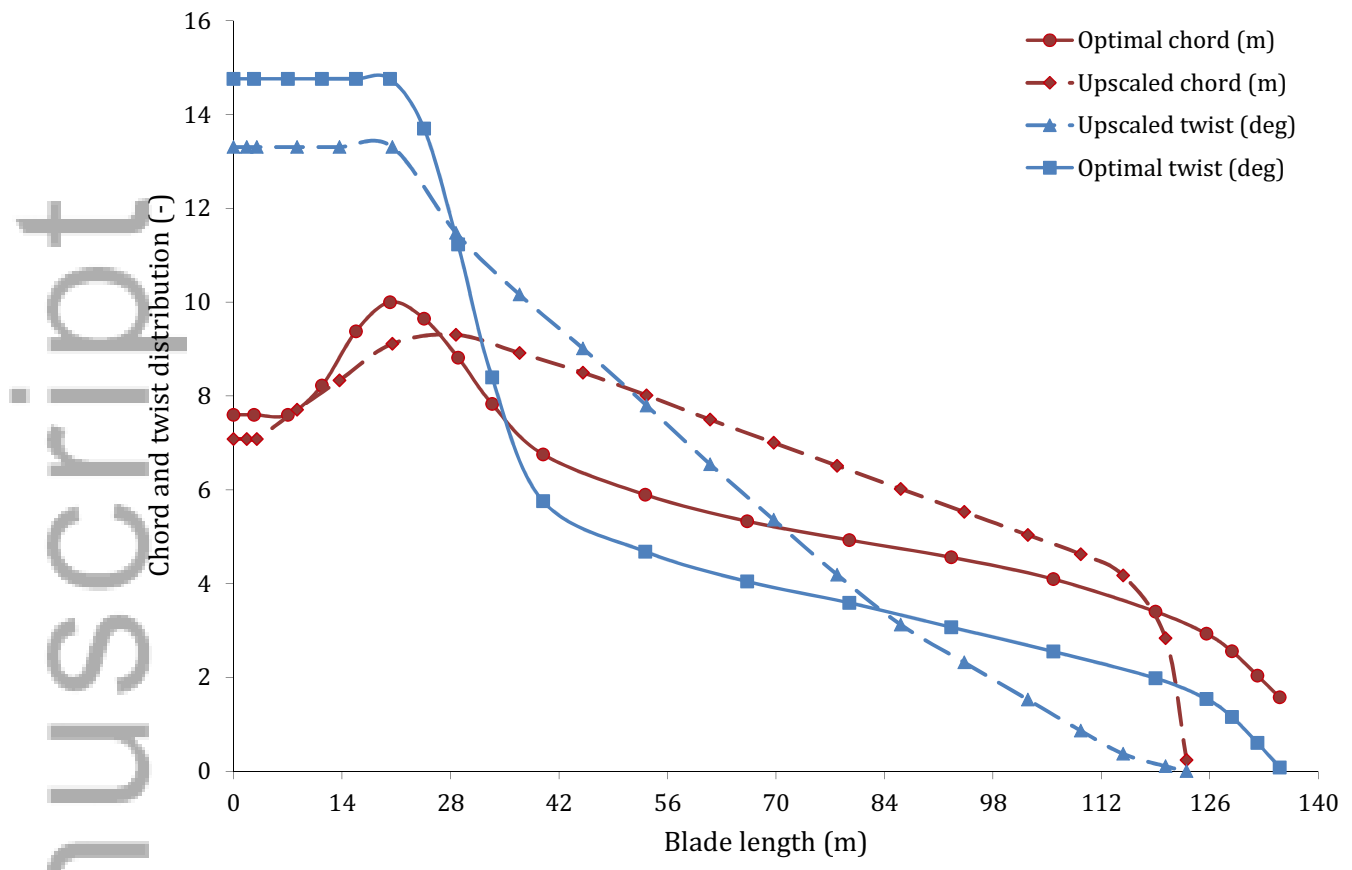

Figure 4: Chord and twist distribution along the span for the linearly upscaled and optimized blades (1)

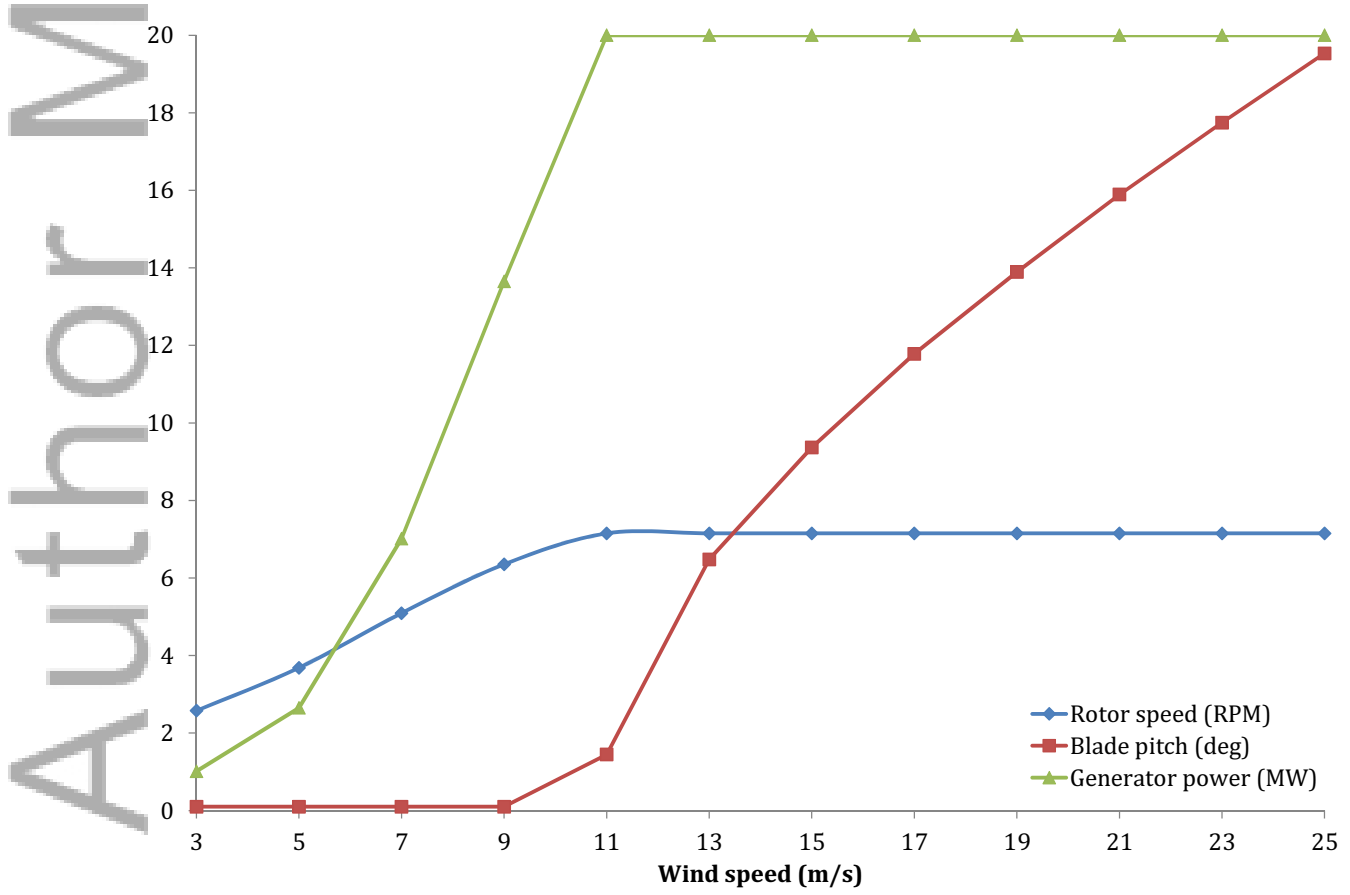

Figure 5: Steady state response for wind speeds form cut-in to cut-out. 
Table 11: Blade structural and aerodynamic data

\begin{tabular}{|c|c|c|c|c|c|c|}
\hline $\begin{array}{l}\text { Section } \\
\text { No. }\end{array}$ & $\begin{array}{l}\text { Radius } \\
(\mathrm{m})\end{array}$ & $\begin{array}{l}\text { Chord } \\
(\mathrm{m})\end{array}$ & $\begin{array}{l}\text { Twist } \\
\text { (deg) }\end{array}$ & $\begin{array}{l}\text { Mass distribution } \\
\qquad\left(\mathrm{kg} / \mathrm{m}^{3}\right)\end{array}$ & $\begin{array}{l}\text { Flap stiffness } \\
\qquad\left(\mathrm{Nm}^{2}\right)\end{array}$ & $\begin{array}{l}\text { Edge stiffness } \\
\qquad\left(\mathrm{Nm}^{2}\right)\end{array}$ \\
\hline-1 & 0.000 & 7.600 & 14.761 & 2313.552 & $5.567 \times 10^{11}$ & $5.567 \times 10^{11}$ \\
\hline & 2.633 & 7.600 & 14.761 & 2311.491 & $5.562 \times 10^{11}$ & $5.562 \times 10^{11}$ \\
\hline & 7.020 & 7.600 & 14.761 & 4302.129 & $8.529 \times 10^{11}$ & $9.695 \times 10^{11}$ \\
\hline 4 & 11.408 & 8.222 & 14.761 & 4529.572 & $1.170 \times 10^{12}$ & $1.058 \times 10^{12}$ \\
\hline 5 & 15.795 & 9.378 & 14.761 & 4845.071 & $1.629 \times 10^{12}$ & $1.323 \times 10^{12}$ \\
\hline & 20.183 & 10.000 & 14.761 & 3758.496 & $4.659 \times 10^{11}$ & $9.361 \times 10^{11}$ \\
\hline & 24.584 & 9.650 & 13.700 & 3620.345 & $4.301 \times 10^{11}$ & $8.799 \times 10^{11}$ \\
\hline & 28.971 & 8.819 & 11.229 & 2594.361 & $8.250 \times 10^{10}$ & $4.776 \times 10^{11}$ \\
\hline & 33.359 & 7.829 & 8.397 & 2289.785 & $5.369 \times 10^{10}$ & $3.424 \times 10^{11}$ \\
\hline & 39.947 & 6.755 & 5.757 & 1959.583 & $3.268 \times 10^{10}$ & $2.279 \times 10^{11}$ \\
\hline 11 & 53.123 & 5.895 & 4.683 & 1623.365 & $1.513 \times 10^{10}$ & $1.343 \times 10^{11}$ \\
\hline 12 & 66.285 & 5.330 & 4.044 & 1433.568 & $8.073 \times 10^{9}$ & $1.056 \times 10^{11}$ \\
\hline 13 & 79.461 & 4.928 & 3.590 & 1312.959 & $6.229 \times 10^{9}$ & $8.612 \times 10^{10}$ \\
\hline 14 & 92.624 & 4.560 & 3.069 & 1204.471 & $4.828 \times 10^{9}$ & $7.105 \times 10^{10}$ \\
\hline & 105.800 & 4.095 & 2.552 & 1026.201 & $2.618 \times 10^{9}$ & $4.166 \times 10^{10}$ \\
\hline & 118.976 & 3.403 & 1.983 & 842.216 & $1.470 \times 10^{9}$ & $2.361 \times 10^{10}$ \\
\hline 17 & 125.550 & 2.932 & 1.541 & 705.200 & $9.121 \times 10^{8}$ & $1.460 \times 10^{10}$ \\
\hline Q & 128.844 & 2.556 & 1.155 & 599.282 & $5.894 \times 10^{8}$ & $9.385 \times 10^{9}$ \\
\hline & 132.138 & 2.039 & 0.602 & 464.475 & $2.910 \times 10^{8}$ & $4.600 \times 10^{9}$ \\
\hline 20 & 135.000 & 1.575 & 0.081 & 350.329 & $1.316 \times 10^{8}$ & $2.061 \times 10^{9}$ \\
\hline
\end{tabular}

\subsection{Support structure data}

The tower and foundation are referred to as the support structure. The soilstructure interaction of the foundation is neglected in this case, and the foundation degrees of freedom at the ground level are constrained to zero. The cost of the foundation system is represented in the design process using engineering models developed by the WindPACT project [26]. These engineering models provide a basis with which the integrity of the design is preserved without loosing too much accuracy in representing the cost.

Table 14 lists the distributed tower properties. The first column lists the location of tower stations measured from the tower base (section 1) to the tower top (section 22) along the tower center-line. Using these data, the first and second natural frequencies of the tower are estimated to be 0.1561 and $1.6802 \mathrm{~Hz}$, respectively. As explained before, the diameter to thickness ratio is constrained to be 160 to avoid buckling. 


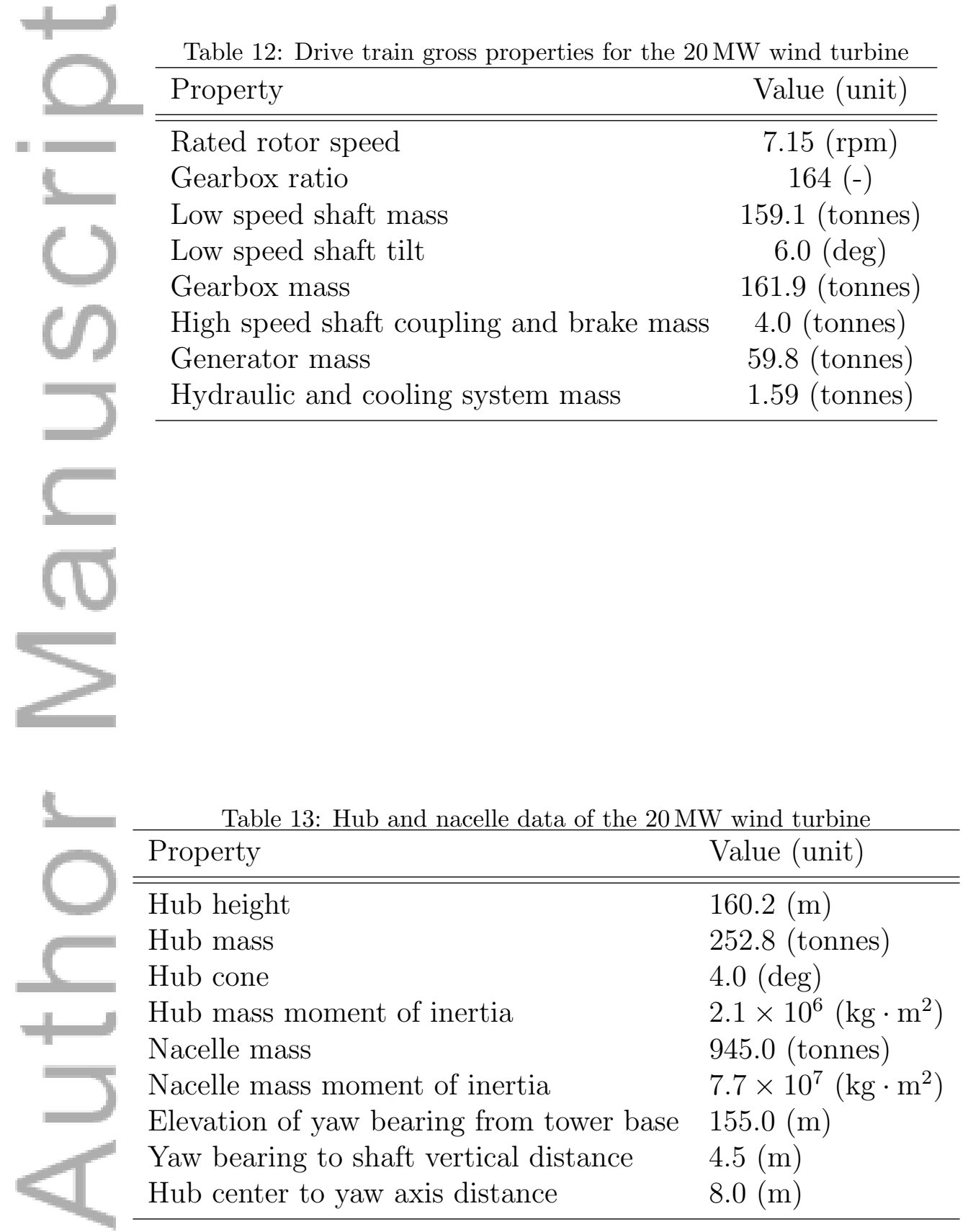


Table 14: Tower data

\begin{tabular}{rrrrr}
\hline \multicolumn{5}{c}{ Table 14: Tower data } \\
\hline Section & Height $(\mathrm{m})$ & Diameter $(\mathrm{m})$ & Thickness $(\mathrm{m})$ & Stiffness $\left(\mathrm{Nm}^{2}\right)$ \\
\hline 1 & 0.000 & 10.000 & 0.063 & $5.179 \times 10^{12}$ \\
2 & 3.875 & 9.918 & 0.062 & $5.011 \times 10^{12}$ \\
3 & 11.625 & 9.748 & 0.061 & $4.676 \times 10^{12}$ \\
4 & 19.375 & 9.571 & 0.060 & $4.346 \times 10^{12}$ \\
5 & 27.125 & 9.388 & 0.059 & $4.022 \times 10^{12}$ \\
6 & 34.875 & 9.197 & 0.057 & $3.706 \times 10^{12}$ \\
7 & 42.625 & 9.000 & 0.056 & $3.398 \times 10^{12}$ \\
8 & 50.375 & 8.788 & 0.055 & $3.089 \times 10^{12}$ \\
9 & 58.125 & 8.559 & 0.053 & $2.780 \times 10^{12}$ \\
10 & 65.875 & 8.321 & 0.052 & $2.483 \times 10^{12}$ \\
11 & 73.625 & 8.080 & 0.051 & $2.207 \times 10^{12}$ \\
12 & 81.375 & 7.845 & 0.049 & $1.961 \times 10^{12}$ \\
13 & 89.125 & 7.622 & 0.048 & $1.748 \times 10^{12}$ \\
14 & 96.875 & 7.420 & 0.046 & $1.570 \times 10^{12}$ \\
15 & 104.625 & 7.233 & 0.045 & $1.418 \times 10^{12}$ \\
16 & 112.375 & 7.053 & 0.044 & $1.282 \times 10^{12}$ \\
17 & 120.125 & 6.880 & 0.043 & $1.160 \times 10^{12}$ \\
18 & 127.875 & 6.714 & 0.042 & $1.052 \times 10^{12}$ \\
19 & 135.625 & 6.556 & 0.041 & $9.565 \times 10^{11}$ \\
20 & 143.375 & 6.406 & 0.040 & $8.723 \times 10^{11}$ \\
21 & 151.125 & 6.266 & 0.039 & $7.985 \times 10^{11}$ \\
22 & 155.000 & 6.200 & 0.039 & $7.652 \times 10^{11}$ \\
\hline
\end{tabular}

This article is protected by copyright. All rights reserved. 


\subsection{Controller data}

Table 15 lists the gross controller data. Rated rotational speed is the only parameter in this table that is directly optimized. The cut-in and cut-out wind speeds, maximum actuator rate of the pitch mechanism, and generator slip in the transition region (region 21/2) are fixed based on sound engineering judgments. All the other properties and parameters are found based on the optimized design data. As an example, the rated tip-speed is calculated by multiplying the optimized values for rated rotational speed and blade length.

\begin{tabular}{ll}
\multicolumn{3}{c}{ Table 15: Controller data } \\
\hline Property & Value (unit) \\
\hline Cut-in, rated and cut-out wind speed & $3,10.7,25(\mathrm{~m} / \mathrm{s})$ \\
Rated tip-speed & $103.3(\mathrm{~m} / \mathrm{s})$ \\
Peak power coefficient & $0.48(-)$ \\
Blade pitch angle at peak power & $0.0(\mathrm{deg})$ \\
Rated rotational speed & $7.15(\mathrm{rpm})$ \\
Rated mechanical power & $21.2(\mathrm{MW})$ \\
Generator slip in transition region & $10(\%)$ \\
Region 2 torque gain constant & $0.11\left(\mathrm{~N} . \mathrm{m} / \mathrm{rpm}^{2}\right)$ \\
Maximum actuator rate of the pitch mechanism & $4.8(\mathrm{deg} / \mathrm{s})$ \\
\hline
\end{tabular}

Figure 6 shows the variation of the PI gains that balance the changes of the aerodynamic power as the wind speed changes. A gain correction factor is used to find the values at any point of interest during operation as presented on the left axis of the graph [49].

\section{Conclusion}

The design of large wind turbines is a challenging task that calls for innovations in the design methodology. The MDO approach used in the present work is such an innovation. The MDO approach enables aerodynamics, structures, and controls to be integrated to achieve the design of a large wind turbine that has the lowest LCoE and satisfies the design constraints. This is an important step for the development of the future large wind turbines, which must be better designed than they are today in order to reduce costs and make such large turbines economically feasible. This goal was achieved by introducing the LCoE as a common multidisciplinary objective function to minimize, rather than separately optimizing the structure for minimum weight or optimizing aerodynamics for maximum energy output.

The linear scaling law is not adequate in providing feasible and size specific optimized wind turbines that are needed to investigate the technical feasibility and economical characteristic of large scale wind turbines. Nonlinear scaling laws can provide a feasible design that also satisfies all the design constraints, but such a design is far 


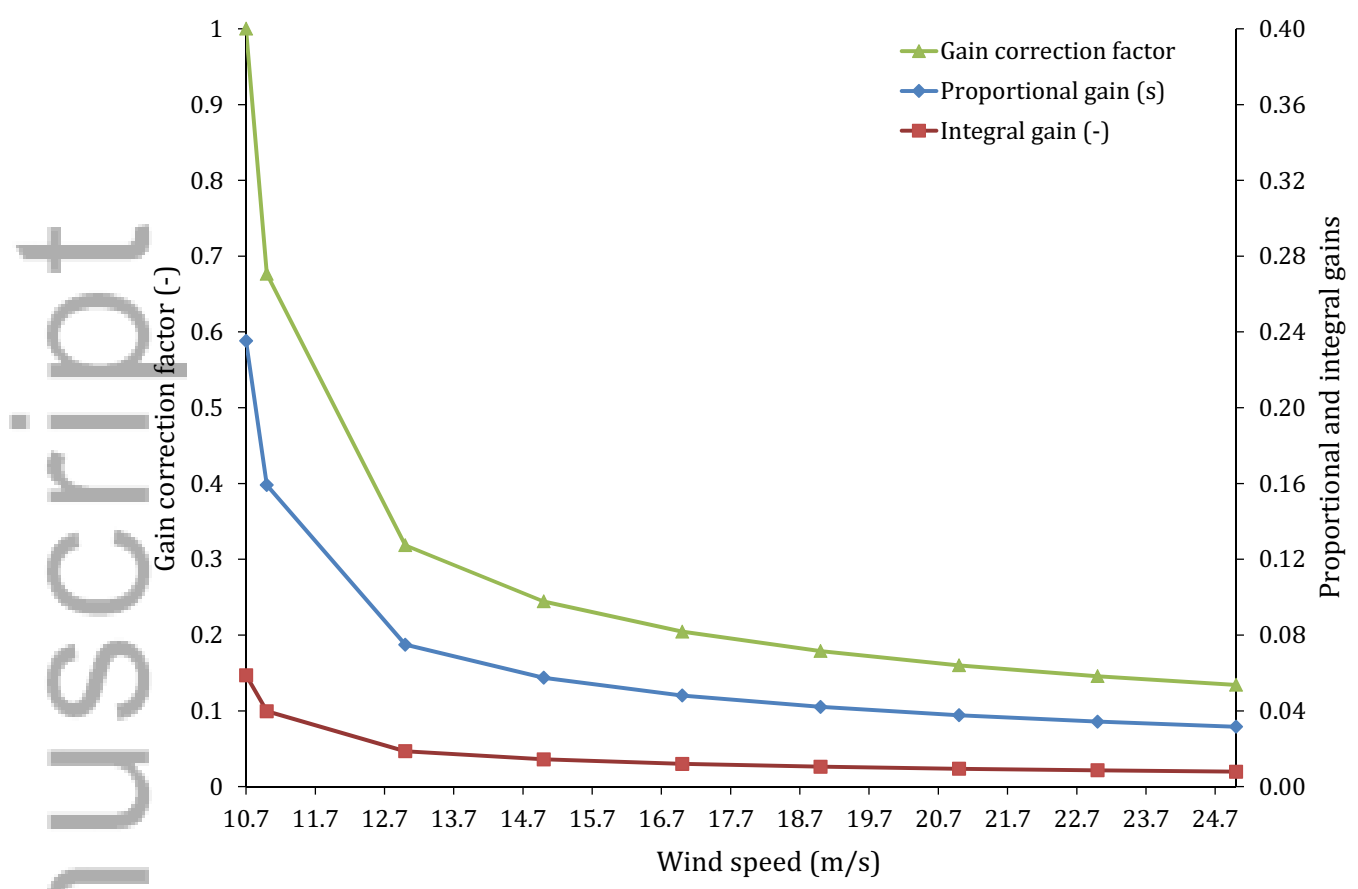

Figure 6: Gain correction and PI gains at different wind turbine operational conditions.

from an optimal design [64, 65]. However, the proposed MDO approach was able to provide a wind turbine optimized for $20 \mathrm{MW}$ power.

In addition, instead of using the traditional methodology to design the tower and rotor separately, the approach of this research enabled the concurrent design of these components. In this work, blade and tower were designed simultaneously resulting in a lower LCoE that if each component were designed separately. This enables the designer to fully understand the technical and economical influence of each component on the design by computing the derivatives of the design constraints and objective function with respect to any variable of interest. This means that the designer can see which variable has the highest impact on any wanted or unwanted function of interest as the design makes progress.

All in all, this has enabled the realization of an optimized $20 \mathrm{MW}$ wind turbine that is feasible, and the results of this research show the technical feasibility of the current wind turbine concept up to 20 MW. Judging from the design constraint values, there seems to be no major technical barrier for this size turbine.

The obtained wind turbine can be used as a baseline design to investigate and compare new technologies or design changes for large turbines, and demonstrate the added value of such turbines. Therefore, the developed $20 \mathrm{MW}$ wind turbine can be used in a similar way as the $5 \mathrm{MW}$ NREL wind turbine is used today by many researchers worldwide. All the corresponding data and simulation files of the common $20 \mathrm{MW}$ research model wind turbine are publicly available to the wind energy community at 
https://github.com/tashuri/20MW-wind-turbine-model.

\section{Future work}

We believe that this $20 \mathrm{MW}$ wind turbine design is the first step toward the realization of larger wind turbines, and that the results of this research will allow other researchers to focus on the detailed design of this turbine and improve it further. There are several areas of improvements in this research in order to have reliable future large wind turbines, which we now describe.

" To calculate the structural properties of the blade, an analytic technique was employed that did not consider effects such as the bend-twist coupling. A more sophisticated method is recommended for the detailed design of the blade. Buckling is a design issue that needs to be considered for the detailed design of the common $20 \mathrm{MW}$ research model. We also ignored aeroelastic instabilities and soil-foundation interaction, which should be considered at the detailed design stage.

The mass and cost models used for this research are developed for wind turbines at smaller scales. Although these models are well suited for the purpose of this research, they may not be representative of future $20 \mathrm{MW}$ wind turbine. Therefore, we recommended the investigation of new models for larger scale wind turbines.

\section{Acknowledgments}

The scientific support of Dr. Anthony Waas from the University of Michigan, USA is acknowledged. This research was financially supported by Agentschap NL, under the INNWIND framework.

\section{References}

[1] Bak C, Bitsche R, Yde A, Kim T, Hansen MH, Zahle F, et al. Light Rotor: The 10-MW reference wind turbine. In: European Wind Energy Conference \& Exhibition. 2012, p. $1-10$.

[2] Zahle F, Bak C, Guntur S, Sørensen NN, Troldborg N. Comprehensive aerodynamic analysis of a $10 \mathrm{mw}$ wind turbine rotor using 3d cfd. In: 32nd ASME Wind Energy Symposium. 2014, p. 1-15.

[3] Peeringa J, Brood R, Ceyhan O, Engels W, de Winkel G. Upwind $20 \mathrm{MW}$ wind turbine pre-design. Tech. Rep.; ECN, Paper No. ECN-E-11-017; 2011.

[4] van Langen P, Hendrinks B. $5 \mathrm{MW}$ UpWind reference wind turbine data. Tech. Rep.; UpWind internal report; 2010.

[5] Dahlhaug OG, Berthelsen PA, Kvamsdal T, Frøyd L, Gjerde SS, Zhang Z, et al. Specification of the NOWITECH $10 \mathrm{MW}$ reference wind turbine. Tech. Rep.; Norwegian Research Centre for Offshore Wind Technology; 2012.

[6] Frøyd L, Dahlhaug O, et al. Rotor design for a $10 \mathrm{MW}$ offshore wind turbine. In: Proceedings of the Twenty-first International Offshore and Polar Engineering Conference. 2011, p. 19-24. 
[7] Muskulus M, Christensen E, Zwick D, Merz K. Improved Tower Design for the NOWITECH 10MW Reference Turbine. In: European Offshore Wind Energy, Frankfurt, Germany. 2013, p. 1-8.

[8] Klair SS. Design of nacelle and rotor hub for NOWITECH 10MW reference turbine. 2013. Master thesis, Norwegian University of Science and Technoloy, Norway.

[9] Bredesen KO. Design of nacelle and yaw bearing for NOWITECH $10 \mathrm{MW}$ reference turbine. 2014. Master thesis, Norwegian University of Science and Technoloy, Norway.

[10] Vatne SR. Aeroelastic instability and flutter for a $10 \mathrm{MW}$ wind turbine. 2011. Master thesis, Norwegian University of Science and Technoloy, Norway.

[11] Frøyd L, Dahlhaug OG, Hansen MH. Prediction of flutter speed on a $10 \mathrm{mw}$ wind turbine. 2011.

[12] Cox K, Echtermeyer A. Structural design and analysis of a $10 \mathrm{MW}$ wind turbine blade. Energy Procedia 2012;24:194-201.

[13] Griffith DT, Ashwill TD. SNL100-00: The Sandia 100-meter all-glass baseline wind turbine blade. Tech. Rep; Sandia National Laboratories, Albuquerque, Report No. SAND2011-3779; 2011.

[14] Griffith DT. SNL100-01: Carbon design studies for the sandia 100-meter blade. Tech. Rep.; Sandia National Laboratories Technical Report, SAND2013-1178; 2013.

[15] Griffith DT. SNL100-02: Advanced core material design studies for the Sandia 100meter blade. Tech. Rep.; Sandia National Laboratories Technical Report, SAND201310162; 2013.

[16] Griffith DT, Richards PW. Investigating the effects of flatback airfoils and blade slenderness on the design of large wind turbine blades. In: European Wind Energy Association, Barcelona, Spain. 2014, p. 1-8.

[17] Loth E, Ichter B, Selig M, Moriarty P. Downwind pre-aligned rotor for a 13.2 MW wind turbine. 2015.

[18] Ashuri T, Zaaijer MB, Martins JR, van Bussel GJ, van Kuik GA. Multidisciplinary design optimization of offshore wind turbines for minimum levelized cost of energy. - Renewable Energy 2014;68:893-905. doi:10.1016/j.renene.2014.02.045.

[19] Fuglsang P, Thomsen K. Site-specific design optimization of 1.5-2.0 MW wind turbines. Journal of solar energy engineering 2001;123(4):296-303.

[20] Maalawi KY, Badr MA. A practical approach for selecting optimum wind rotors. Renewable energy 2003;28(5):803-22.

[21] Méndez J, Greiner D. Wind blade chord and twist angle optimization using genetic algorithms. In: Fifth International Conference on Engineering Computational Technology, Las Palmas de Gran Canaria, Spain. 2006, p. 12-5. 
[22] Kenway GKW, Martins JRRA. Aerostructural shape optimization of wind turbine blades considering site-specific winds. In: Proceedings of the 12th AIAA/ISSMO Multidisciplinary Analysis and Optimization Conference. Victoria, BC; 2008, p. 1-12. AIAA 2008-6025.

[23] Xudong W, Shen WZ, Zhu WJ, Sorensen JN, C J. Shape optimization of wind turbine blades. Wind energy 2009;12(8):781-803.

[24] Maki K, Sbragio R, Vlahopoulos N. System design of a wind turbine using a multi-level " optimization approach. Renewable Energy 2012;43(12):101-10.

[25] Ashuri T, Zaaijer MB. Review of design concepts, methods and considerations of offshore wind turbines. In: European Offshore Wind Conference and Exhibition, Berlin, Germany. 2007, p. 1-10.

[26] Fingersh L, Hand M, Laxson A. Wind turbine design cost and scaling model. Tech. Rep.; National Renewable Energy Laboratory, NREL/TP-500-40566, Golden, Colorado; 2006.

[27] Poore R, Lettenmaier T. Alternative design study report: WindPACT Advanced wind turbine drive train designs study. Tech. Rep.; National Renewable Energy Laboratory, NREL/SR-500-33196, Golden, CO.; 2003.

[28] Griffin DA. Windpact turbine design scaling studies technical area 1: Composite blades for 80-to 120-meter rotor. Tech. Rep.; National Renewable Energy Laboratory, NREL/SR-500-29492, Golden, CO.; 2001.

[29] Smith K. Windpact turbine design scaling studies technical area 2: Turbine, rotor, and blade logistics. Tech. Rep.; National Renewable Energy Laboratory, NREL/SR-50029439, Golden, CO.; 2001.

[30] Bywaters G, John V, Lynch J, Mattila P, Norton G, Stowell J, et al. Northern power systems windpact drive train alternative design study report; period of performance: April 12, 2001 to January 31, 2005. Tech. Rep.; National Renewable Energy Laboratory, NREL/SR-500-35524, Golden, CO.; 2004.

[31] Shafer D, Strawmyer K, Conley R, Guidinger J, Wilkie D, Zellman T, et al. Windpact turbine design scaling studies: Technical area 4-balance-of-station cost. Tech. Rep.; - National Renewable Energy Laboratory, NREL/SR-500-29950, Golden, CO.; 2001.

[32] Brand AJ. Offshore wind atlas of the Dutch part of the North sea. Tech. Rep.; ECNM-09-050, Energy research Centre of the Netherlands, Petten; 2008.

[33] Martins JRRA, Lambe AB. Multidisciplinary design optimization: A survey of architectures. AIAA Journal 2013;51(9):2049-75. doi:10.2514/1. J051895.

[34] Lambe AB, Martins JRRA. Extensions to the design structure matrix for the description of multidisciplinary design, analysis, and optimization processes. Structural and Multidisciplinary Optimization 2012;46:273-84. doi:10.1007/s00158-012-0763-y. 
[35] Nijssen R, Zaaijer M, Bierbooms W, Van Kuik G, Van Delft D, van Holten T. The application of scaling rules in up-scaling and marinisation of a wind turbine. In: European Wind Energy Conference and Exhibition (EWEC). 2001, p. 1-4.

[36] Teng JG, Rotter JM. Buckling of thin metal shells. CRC Press; 2006.

[37] Bhattacharya S, Carrington T, Aldridge T. Buckling considerations in pile design. In: ISFOG: Frontiers in Offshore Geotechnics. 2005, p. 815-21.

[38] Ashuri T. Beyond classical upscaling: Integrated aeroservoelastic design and optimization of large offshore wind turbines. PhD thesis; Delft University of Technology; the Netherlands; 2012.

[39] Kooijman H, Lindenburg C, Winkelaar D, Van der Hooft E. DOWEC 6 MW predesign: Aero-elastic modelling of the DOWEC $6 \mathrm{MW}$ pre-design in PHATAS. Tech. Rep; DOWEC Dutch Offshore Wind Energy Converter 1997-2003 Public Reports; 2003.

[40] Fleury C. CONLIN: An efficient dual optimizer based on convex approximation concepts. Structural and Multidisciplinary Optimization 1989;1(2):81-9.

[41] Birgin EG, Martinez JM. Improving ultimate convergence of an augmented Lagrangian method. Optimization Methods and Software 2008;23(2):177-95.

[42] Jonkman BJ, Buhl ML. Turbsim user's guide. Tech. Rep.; National Renewable Energy Laboratory, NREL/TP-500-41136, Golden, Colorado; 2007.

[43] Laino DJ, Hansen AC. User's guide to the wind turbine dynamics aerodynamics computer software AeroDyn. Tech. Rep.; Windward Engineering LLC, Prepared for the National Renewable Energy Laboratory under Subcontract No. TCX-9-29209-01, Salt Lake City, UT; 2002.

[44] Viterna LA, Janetzke DC. Theoretical and experimental power from large horizontalaxis wind turbines. Tech. Rep.; National Aeronautics and Space Administration, Cleve-

[45] Jonkman JM, Buhl ML. FAST user's guide. Tech. Rep.; National Renewable Energy Laboratory, NREL/EL-500-29798, Golden, Colorado; 2004.

[46] Bir GS. User's guide to BModes. Tech. Rep.; National Renewable Energy Laboratory, NREL/TP-500-39133, Golden, Colorado; 2007.

[47] Buhl ML. Crunch user's guide. Tech. Rep.; National Renewable Energy Laboratory, NREL/EL-500-30122, Golden, Colorado; 2003.

[48] Frendahl M, Rychlik I. Rainflow analysis: Markov method. International journal of fatigue $1993 ; 15(4): 265-72$. 
[49] Ashuri T, Zaaijer MB, van Bussel GJW, van Kuik GAM. Controller design automation for aeroservoelastic design optimization of wind turbines. In: The science of making torque from wind, Crete, Greece. 2010, p. 1-7.

[50] Ashuri T, Rotea M, Xiao Y, Li Y, Ponnurangam CV. Wind turbine performance decline and its mitigation via extremum seeking controls. In: $34^{\text {th }}$ wind energy sympossium. American Institute of Aeronautics and Astronautics, AIAA; 2016, p. 1-11.

[51] Van Rooij R, Timmer W. Roughness sensitivity considerations for thick rotor blade = airfoils. Journal of solar energy engineering 2003;125(4):468-78.

[52] Timmer W, Schaffarczyk A. The effect of roughness at high reynolds numbers on the performance of aerofoil du 97-w-300mod. Wind Energy 2004;7(4):295-307.

[53] Du Z, Selig M. A 3-D stall-delay model for horizontal axis wind turbine performance prediction. In: AIAA-98-0021. 1998, p. 9-21.

[54] Eggers AJ, Chaney K, Digumarthi R, Incorporated R. An assessment of approximate modeling of aerodynamic loads on the UAE rotor. In: 41st Aerospace Sciences Meeting and Exhibit, Reno, NV. 2003, p. 6-9.

[55] Leishman JG, Beddoes TS. A semi-empirical model for dynamic stall. Journal of the American Helicopter Society 1989;34(3):3-17.

[56] Ashuri T, Zaaijer MB, van Bussel GJW, van Kuik GAM. An analytical model to extract wind turbine blade structural properties for optimization and up-scaling studies. In: The science of making torque from wind, Crete, Greece. 2010, p. 1-7.

[57] IEC61400 . Wind turbines, part 3: Design requirements for offshore wind turbines. 2009.

[58] Ashuri T, van Bussel GJW, Mieras S. Development and validation of a computational model for design analysis of a novel marine turbine. Wind Energy 2013;16(1):77-90. doi: $10.1002 /$ we 530 .

[59] van der Meulen MB, Ashuri T, van Bussel GJW, Molenaar DP. Influence of nonlinear irregular waves on the fatigue loads of an offshore wind turbine. In: The Science of Making Torque from Wind, Oldenburg, Germany. 2012, p. 1-10. doi:10.13140/2.1. 3034.5606 .

[60] Haghi R, Ashuri T, van der Valk PL, Molenaar DP. Integrated multidisciplinary constrained optimization of offshore support structures. In: The science of Making torque from wind; vol. 555. Journal of Physics, 555 012046; 2012, p. 1-10. doi:10.1088/1742-6596/555/1/012046.

[61] Muskulus M. The full-height lattice tower concept. Energy Procedia 2012;24:371-7.

[62] de Vries W, Vemula NK, Passon P, Fischer T, Kaufer D, Matha D, et al. Final report wp4. 2: Support structure concepts for deep water sites. Tech. Rep.; UpWind project; 2011. 
[63] Van Der Tempel J. Design of support structures for offshore wind turbines. PhD thesis; Delft University of Technology; the Netherlands; 2006.

[64] Capponi PC, Ashuri T, van Bussel GJW, Kallesøe B. A non-linear upscaling approach for wind turbine blades based on stresses. In: European Wind Energy Conference and Exhibition, Brussels, Belgium. European Academy of Wind Energy; 2011, p. 1-8.

[65] Ashuri T, Zaaijer MB. Size effect on wind turbine blade's design drivers. In: European Wind Energy Conference and exhibition, Brussels, Belgium. 2008, p. 1-6.
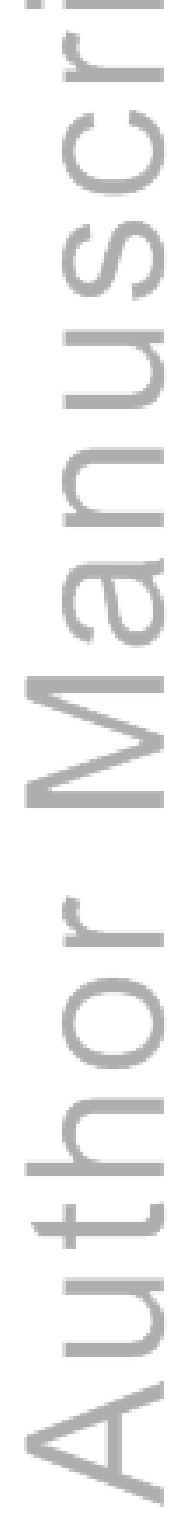